\title{
Successful radiopeptide targeting of metastatic anaplastic meningioma: Case report
}

\author{
Amir Sabet ${ }^{1 *}$, Hojjat Ahmadzadehfar ${ }^{1}$, Ulrich Herrlinger ${ }^{2}$, Winfried Wilinek ${ }^{3}$, Hans-Jürgen Biersack ${ }^{1}$ and \\ Samer Ezziddin ${ }^{1}$
}

\begin{abstract}
A patient with anaplastic meningioma and lung metastases resistant to conventional treatment underwent radiopeptide therapy with 177Lu- DOTA-octreotate in our institute. The treatment resulted in significant improvement in patient's quality of life and inhibition of tumor progression. This case may eventually help to establish the value of radiopeptide therapy in patients with this rare condition.
\end{abstract}

Keywords: 18F-FDG-PET/CT, anaplastic meningioma, $111 \mathrm{ln}$-DTPA-octreotide, radio receptor therapy

\section{Background}

Meningiomas are generally slow-growing lesions that arise from intracranial and spinal meninges. They are usually perceived as benign tumours for which radical surgery is the treatment of choice [1]. However, they may occasionally behave aggressively in atypical or malignant meningiomas, invading the brain and/or metastasising outside the CNS, which occurs in only $0.01 \%$ of all cases [2]. The most common extracranial location of metastasis is the lung followed by liver, lymph nodes and bones [3,4]. Meningiomas present ideal targets for somatostatin receptor scintigraphy (SRS) with 111In-DTPA-octreotide. However, the value of the radioreceptor therapy using radiolabeled somatostatin analog $177 \mathrm{Lu}-\mathrm{DOTA}$-octreotate is not yet well established in patients with metastasized or inoperable meningiomas $[5,6]$. Here, we present a patient with metastatic anaplastic meningioma who benefited from radiopeptide targeting.

\section{Case presentation}

A 62 year old female with intracranial anaplastic meningioma was referred to our department for a restaging with 18F-fluorodeoxyglucose (FDG)-PET/CT. The patient suffered from a protrusio bulbi of the left eye and progressive facial pain. No conventional treatment option could be

\footnotetext{
* Correspondence: amir.sabet@ukb.uni-bonn.de

'Department of Nuclear Medicine, University Hospital Bonn, Sigmund-FreudStrasse 25, 53105 Bonn, Germany

Full list of author information is available at the end of the article
}

offered to the patient, who had undergone multiple surgical resections and percutaneous radiation before.

The fused PET/CT images (Biograph; Siemens Medical Solutions Inc) manifested multifocal accumulation in the left temporal region with local bone infiltration. Furthermore, they demonstrated multiple pulmonary metastases in the upper lobe of the left lung (Figure 1). In view of these findings, including the diagnosis of pulmonary metastases, the patient was referred for SRS to evaluate the option of a palliative radiopeptide therapy with $177 \mathrm{Lu}$ - DOTA-octreotate. SRS images showed strong uptake in the left temporal region as well as in the upper lobe of the left lung, consistent with the PET/ CT findings (Figure 2). Due to the abundance and high affinity of somatostatin receptors (sstr), we performed radiopeptide therapy with $177 \mathrm{Lu}$ - DOTA-octreotate consisting of 3 cycles (cumulative dose: $691 \mathrm{mCi}$ ) without any serious side effects (Figure 3 ). The patient experienced a dramatic reduction of facial pain assessed by visual analogue scale (VAS) as well as a significant improvement in quality of life with a $30 \%$ increase in her performance status using karnofsky scoring 6 weeks after commencement of the treatment. Disease stabilization could also be achieved, according to functional MD Anderson criteria, evaluated 3 months after termination of radiopeptide therapy [7]

\section{Discussion}

The local recurrence rate of meningioma is determined by the extent of the resection, histopathological grade 


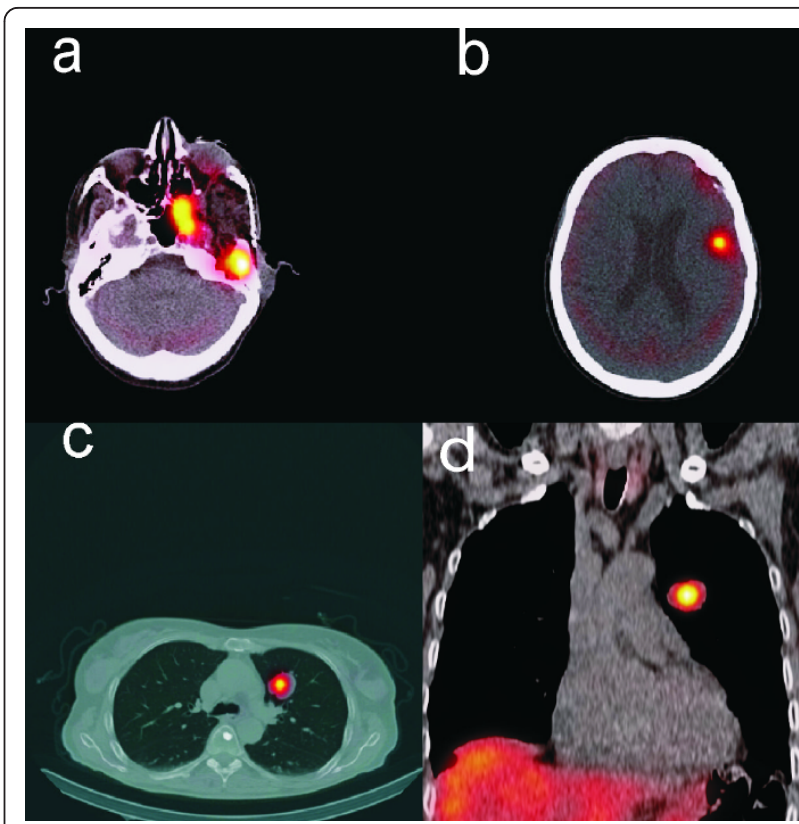

Figure 2 SPECT/CT images of somatostatin receptor scintigraphy display avid uptake in the intracranial meningioma ( $2 a$ and $b$ ) as well as in the pulmonary metastases ( $2 c$ and $d)$.

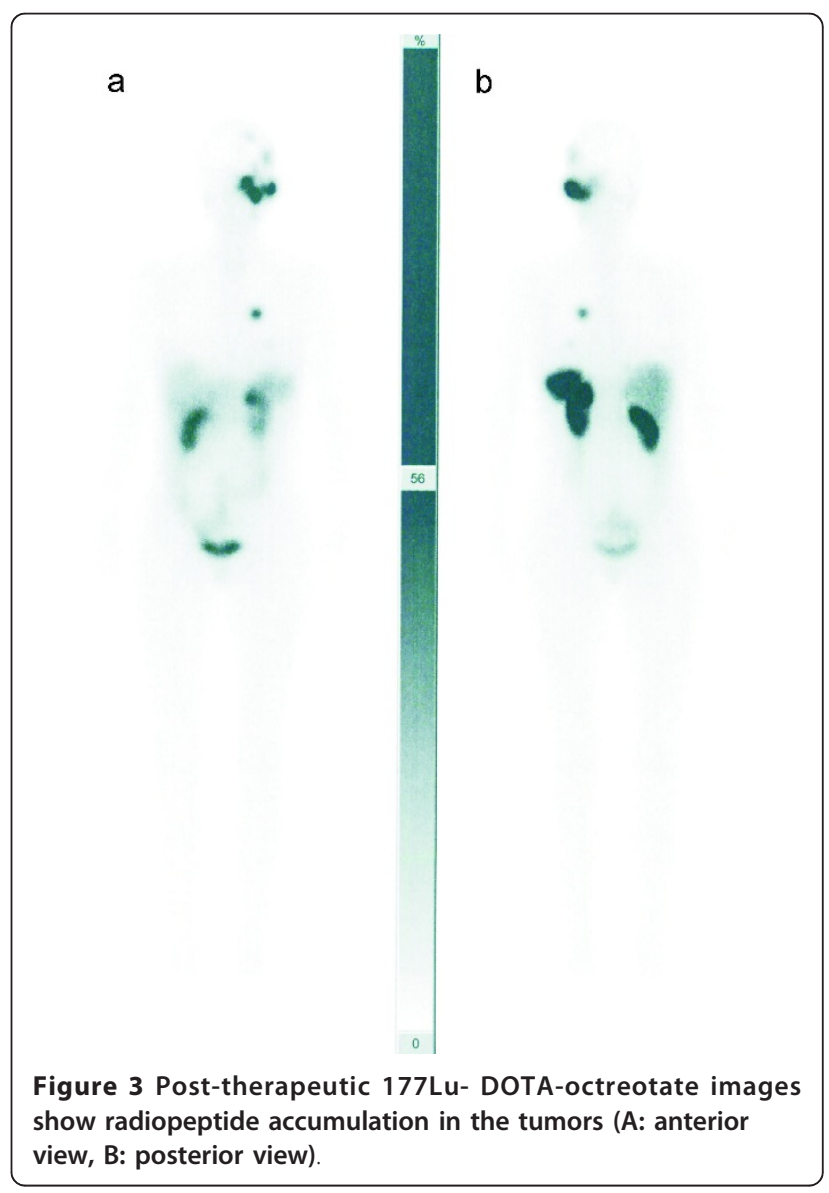

show radiopeptide accumulation in the tumors ( $A$ : anterior view, B: posterior view) and biological aggressiveness of the tumor $[8,9]$. Once a meningioma recurs, it is more likely to recur again later, resulting in a poor prognosis of the patient [10]. 18FFDG-PET/CT has been commonly used in patients with primary tumours of central nervous system including meningioma for tumor grading, determination of the prognosis and discrimination of tumor recurrence from radiation necrosis $[11,12]$. With their high sstr density and location outside the blood-brain barrier, meningiomas also present ideal targets for SRS with 111InDTPA-octreotide which is the main imaging technique for neuro endocrine tuomors (NETs) but may be also used in other tumors expressing somatostatin receptors such as neuroblastoma, pheochromocytoma and paraganglioma [13-15]. This procedure is used apart from staging and monitoring the effect of treatment for selecting patients for peptide receptor radionuclide therapy (PRRT), primarily used in gastroenteropancreatic 
NETs with very encouraging results. The value of PRRT is not yet well established in patients with meningiomas [5]. Our patient experienced a dramatic symptomatic relief as well as a significant improvement in quality of life following the PRRT along with inhibition of tumor progression.

\section{Conclusions}

The presented case may help to establish the value of PRRT in patients with the rare condition of anaplastic meningioma.

\section{Consent}

Written informed consent was obtained from the patient for publication of this Case report and any accompanying images. A copy of the written consent is available for review by the Editor-in-Chief of this journal.

\footnotetext{
Author details

${ }^{1}$ Department of Nuclear Medicine, University Hospital Bonn, Sigmund-FreudStrasse 25, 53105 Bonn, Germany. ${ }^{2}$ Department of Neurooncology, University Hospital Bonn, Sigmund-Freud-Strasse 25, 53105 Bonn, Germany. ${ }^{3}$ Department of Radiology, University Hospital Bonn, Sigmund-Freud-Strasse 25, 53105 Bonn, Germany.
}

\section{Authors' contributions}

Conception of the case report: A.S., S.E., HJ.B.; Collection and assembly of data: H.A., W.W., U.H.; Literature review and interpretation of data: A.S. S.E., H. A.; Drafting of the article: A.S., HJ.B., S.E.; Critical revision of the article for important intellectual content: U.H., H.A. W.W. All authors have read and approved the final manuscript.

\section{Competing interests}

The authors declare that they have no competing interests.

Received: 12 May 2011 Accepted: 12 August 2011

Published: 12 August 2011

\section{References}

1. Alvarez F, Roda JM, Perez Romero M, Morales C, Sarmiento MA, Blazquez MG: Malignant and atypical meningiomas: a reappraisal of clinical, histological, and computed tomographic features. Neurosurgery 1987, 20(5):688-694.

2. Figueroa BE, Quint DJ, McKeever PE, Chandler WF: Extracranial metastatic meningioma. Br J Radiol 1999, 72(857):513-516.

3. Karasick JL, Mullan SF: A survey of metastatic meningiomas. J Neurosurg 1974, 40(2):206-212

4. Kodama K, Doi O, Higashiyama M, Horai T, Tateishi R, Nakagawa H: Primary and metastatic pulmonary meningioma. Cancer 1991, 67(5):1412-1417.

5. van Essen M, Krenning EP, Kooij PP, et al: Effects of therapy with [177LuDOTA0, Tyr3]octreotate in patients with paraganglioma, meningioma, small cell lung carcinoma, and melanoma. J Nucl Med 2006, 47(10):1599-1606.

6. Bartolomei M, Bodei L, De Cicco C, et al: Peptide receptor radionuclide therapy with (90)Y-DOTATOC in recurrent meningioma. Eur I NuCl Med Mol Imaging 2009, 36(9):1407-1416.

7. Costelloe CM, Chuang HH, Madewell JE, Ueno NT: Cancer Response Criteria and Bone Metastases: RECIST 1.1, MDA and PERCIST. J Cancer 2010, 1:80-92.

8. Marosi C, Hassler M, Roessler K, et al: Meningioma. Crit Rev Oncol Hemato 2008, 67(2):153-171.

9. Takahashi JA, Ueba T, Hashimoto N, Nakashima Y, Katsuki N: The combination of mitotic and Ki-67 indices as a useful method for predicting short-term recurrence of meningiomas. Surg Neurol 2004, 61(2):149-155, discussion 155-146

10. Commins DL, Atkinson RD, Burnett ME: Review of meningioma histopathology. Neurosurg Focus 2007, 23(4):E3.

11. Delbeke D, Meyerowitz C, Lapidus RL, et al: Optimal cutoff levels of F-18 fluorodeoxyglucose uptake in the differentiation of low-grade from high-grade brain tumors with PET. Radiology 1995, 195(1):47-52

12. Hustinx R, Pourdehnad M, Kaschten B, Alavi A: PET imaging for differentiating recurrent brain tumor from radiation necrosis. Radiol Clin North Am 2005, 43(1):35-47.

13. Sisson JC, Shulkin BL: Nuclear medicine imaging of pheochromocytoma and neuroblastoma. Q J Nucl Med 1999, 43(3):217-223.

14. Schmidt M, Scheidhauer $K$, Luyken $C$, et al: Somatostatin receptor imaging in intracranial tumours. Eur J Nucl Med 1998, 25(7):675-686.

15. Nathoo N, Ugokwe K, Chang AS, et al: The role of 111 indium-octreotide brain scintigraphy in the diagnosis of cranial, dural-based meningiomas. J Neurooncol 2007, 81(2):167-174

doi:10.1186/1748-717X-6-94

Cite this article as: Sabet et al: Successful radiopeptide targeting of metastatic anaplastic meningioma: Case report. Radiation Oncology 2011 6:94.

\section{Submit your next manuscript to BioMed Central and take full advantage of:}

- Convenient online submission

- Thorough peer review

- No space constraints or color figure charges

- Immediate publication on acceptance

- Inclusion in PubMed, CAS, Scopus and Google Scholar

- Research which is freely available for redistribution 